\title{
Untypical Manifestations of Granulomatosis with Polyangiitis-A Review of the Literature
}

\author{
Joanna Miłkowska-Dymanowska ${ }^{1}$ - Paulina Laskowska ${ }^{1}$ - Mikołaj Rzuczkowski ${ }^{1}$ - Adam J. Białas ${ }^{1}$. \\ Wojciech J. Piotrowski ${ }^{1}$ - Paweł Górski ${ }^{1}$
}

Accepted: 24 May 2019 /Published online: 11 June 2019

(C) The Author(s) 2019

\begin{abstract}
Granulomatosis with polyangiitis (GPA, previously known as Wegener's granulomatosis) is a type of ANCA-associated vasculitis that affects small- to medium-sized vessels. GPA occurs with a prevalence of 24-152:1000000. The disease affects all races at every age. Various factors may have an impact on the etiology of GPA which is treated as an autoimmune disease. Genetic factors, infectious agents (like Staphylococcus aureus), environmental factors (like silica, hydrocarbons, fumes, pesticides, and farming) are considered elements for the development of the disease. Mostly, GPA affects the upper and lower respiratory tracts and kidneys and associated with otorhinolaryngological and renal manifestations. However, numerous untypical manifestations may also occur. Our review is aimed at discussing the most significant of them, including the neurological, cardiac, gastrointestinal tract, joints and muscles, skin, and ophthalmological manifestations. The whole literature was searched in PubMed. It has been used phrases granulomatosis with polyangiitis', Wegener's granulomatosis' and GPA'. The initial research for every sentence yielded subsequently, 4472, 5043, and 7110 results. Only studies with available full text were retrieved. After a threestage evaluation including a language evaluation, a heading evaluation, and an abstract evaluation, we obtained 139 relevant papers on which our review is based. GPA is a huge challenge for contemporary diagnostics and medicine. Our review is aimed at demonstrating the multiplicity of untypical manifestations and proving that every doctor may come into contact with a patient with GPA.
\end{abstract}

Keywords Granulomatosis with polyangiitis $\cdot$ GPA $\cdot$ Central nervous system $\cdot$ Untypical manifestations $\cdot$ Skin

Joanna Miłkowska-Dymanowska and Paulina Laskowska contributed equally to this work.

This article is part of the Topical Collection on Medicine

Joanna Miłkowska-Dymanowska

joanna.milkowska-dymanowska@umed.lodz.pl

Paulina Laskowska

aiko.02305@gmail.com

Mikołaj Rzuczkowski

mikolajk2019@gmail.com

Adam J. Białas

adam.bialas@umed.lodz.pl

Wojciech J. Piotrowski

wojciech.piotrowski@umed.lodz.pl

Paweł Górski

pawel.gorski@umed.lodz.pl

1 Department of Pneumology and Allergy, Medical University of Łódź, 22 Kopcinski Avenue, 90-153 Łódź, Poland

\section{Background}

Granulomatosis with polyangiitis is an autoimmune disease presenting with various symptoms and signs. This multiplicity of manifestations may be misleading and, in consequence, delays establishment of proper diagnosis and treatment. We would like to present a literature review providing untypical manifestations of GPA.

We searched PubMed with the phrases, granulomatosis polyangiitis', GPA', and Wegener's granulomatosis' and with each of the preceding phrases appended with each of the following additions nervous system', heart', gastrointestinal tract', joints', muscles', skin' and eyes' (e.g. granulomatosis polyangiitis nervous system', granulomatosis polyangiitis heart'). Only articles with available abstracts and full text were considered. For related titles, the abstracts were reviewed and, if still appropriate, the articles were added to our work in full version. References within the selected articles were also reviewed and accepted depending on their accuracy. Ultimately, we used 139 articles in our work. 


\section{Introduction}

Granulomatosis with polyangiitis (GPA, previously known as Wegener's granulomatosis) affects small-sized to mediumsized vessels causing vasculitis [1,2]. Vessels of the upper or lower airways or whole respiratory tract and kidneys are involved with a prevalence of $90 \%$ [3] and 78\% [4], respectively. The biopsy findings include neutrophilic vasculitis with necrosis and multinucleated giant cells and mononuclear infiltrate in walls of vessels affected with fibrinoid necrosis $[5,6]$.

GPA occurs with a prevalence from 24 to $152: 1000000$ [7-13]. Interestingly, the frequency of its prevalence depends on geographic position [14], for example, there is a greater frequency in the north of Europe. The disease affects all races. However, Caucasians are mostly affected [1]. An age-specific peak depends on a study. Some authors observed the highest tendency between 55 and 64 years [15] and others between 45 and 60 years [16]. But GPA can occur among patients at every age [17].

GPA is a type of ANCA-associated vasculitis. ANCA are antineutrophil cytoplasmic autoantibodies and can be directed against the neutrophil serine proteinase-3 (PR3-cANCA) and against the neutrophil enzyme myeloperoxidase (MPO) [18]. A positive result for these types of antibodies may be obtained for about $70-80 \%$ and $10 \%$ of patients respectively [19]. The diagnostic criteria were not distinguished. The American College of Rheumatology established the following classification criteria for GPA: (1) abnormal urinary sediment, (2) abnormal findings on chest radiograph, (3) oral ulcers or nasal discharge, and (4) granulomatous inflammation on biopsy [20]. Clinical picture suggesting a vasculitis accompanied by a positive ANCA test and a positive biopsy result showing evidence of necrotizing vasculitis, necrotizing glomerulonephritis, or granulomatous inflammation suggests strongly a diagnosis of GPA [21].

Various factors may have an impact on the etiology of GPA which is treated as an autoimmune disease [22]. Genetic factors [23], infectious agents (like Staphylococcus aureus [24]), environmental factors (like silica [24], hydrocarbons [25], fumes [26], pesticides [26], and farming [27]) are considered elements for the development of GPA.

GPA is known as a disease affecting the upper and lower respiratory tracts and kidneys and associated with otorhinolaryngological and renal manifestations. But it does not mean that GPA is limited only to these organs. Vessels, for example, in the heart, skin, eyes, muscles, gastrointestinal tract, and breast may be involved as well $[28,29]$.

The mortality of untreated GPA is high, so the issue of effective treatment is vital. EULAR recommends assigning patients with GPA to different levels of severity to allow for adjusted treatment [30] which consists of two phases: the induction phase and the maintenance phase. The first phase is aimed at inducing the remission $[16,31]$. EULAR recommends a combination of cyclophosphamide (intravenous or oral) and prednisolone [30]. The above therapy will be preceded by an intravenous bolus of methylprednisolone, if the disease is refractory or severe and the cardiovascular patient's condition allows for it. The boli can be administered once daily for 3 days. Once the proper time of treatment has elapsed, the dose of oral prednisolone should be gradually reduced [16]. Immunosuppressive agents like cyclophosphamide play important roles, but cause side effects [32] (infections, bone marrow suppression, cystitis [33]) and is toxic. EULAR recommends antiemetic therapy if cyclophosphamide is intravenous. The patient should drink a lot of fluid to prevent the concentration of harmful substances in urine. However, if contraindications exist, then cyclophosphamide can be swapped for methotrexate, but not in organ-threatening or life-threatening forms. In early systemic GPA, the patient can be treated with methotrexate. It is advantageous to administer folic or folinic acid during methotrexate therapy [30]. Rituximab is effective as an immunosuppressive agent, so it can be used as an alternative for cyclophosphamide [16, 33]. In the second phase, EULAR also recommends a combined therapy. The maintenance treatment consists of low-dose glucocorticoids and either azathioprine, leflunomide, or methotrexate. The second phase should persist at least 18 months [30]. Refractory cases are treated with rituximab, TNF- $\alpha$ antagonists, intravenous immunoglobulin, deoxyspergualin, and anti-thymocyte globulin [32]. Plasma exchange is used in selected cases with rapidly progressive renal disease [30] and only additionally to prescribed therapy [33]. However, its effectiveness has not been well studied [30, 33].

\section{Neurological Involvement}

Neurological involvement was observed in 22 to 54\% [34-37] of patients with GPA. The results received before the use of an adequate therapy were the highest. Later researches indicate smaller prevalence [37]. The changes are not only an effect of vasculitis, because the granulomatous lesions can spread from their adjacent primary places like the nasal cavity, paranasal sinuses, and orbit and involve the optic nerve, optic chiasm, pituitary gland, nasal vestibule, base of the brain, and meninges [38]. The entanglement of lower cranial nerves and meninges may come from a spreading contiguous primary granulomatous lesion located in the middle ear [36]. Moreover, a granulomatous lesion remote from nasal granulomas can affect meninges, cranial nerves, the brain, and parietal bone. According to the results of one study which distinguished these three possible pathogenic processes, vasculitis occurred in $28 \%$ of patients, granulomatous lesions spreading through the walls of the nasal cavity occurred in $26 \%$ of patients, while remote granulomatous formations affecting cranial and cerebral structures concerned only $4 \%$ [38]. 
Neurological involvement can be divided into peripheral nervous system involvement with a prevalence of between 10.6 and $43.8 \%[3,35,37,39-42]$ and into central nervous system involvement affecting $2-11 \%$ of patients [3, 37, 41-43]. Vasculitis underlies peripheral neuropathy [38]. The median time from the beginning of GPA to neuropathy is 8.4 months [35]. The spectrum of changes in the nervous system includes various signs and symptoms. Patients complain of paresthesia, numbness, burning pain, and paresis whereas, there is a group which does not display any symptoms (18\%). Their diagnosis of the peripheral nervous system involvement is based on clinical and electrophysiologic tests. The impairment of touch sensation and absence of tendon reflexes are the most common findings (respectively $66 \%$ and 50\%). Other clinical findings include impairment of pain sensation, vibration sensation, temperature sensation, paresis, and muscular atrophy. These ailments can be the result of axonal neuropathy (definitely more often) or demyelinating neuropathy. It is possible for both of these two lesions to occur at the same time [42]. A large study done by Nishino et al. showed that the most common peripheral neuropathy is multiple mononeuropathy with a prevalence of $80 \%$ in patients with peripheral nervous system involvement. In this paper, the damages concerned the peroneal, tibial, ulnar, median, radial, and femoral nerves. Distal symmetrical sensorimotor polyneuropathy occurs in $11 \%$ of cases with peripheral neuropathy [35]. In contrast to the frequencies of types of neuropathy, another paper states that symmetrical sensorimotor polyneuropathy befalls patients slightly more frequently (55\%), whereas mononeuropathy happens in $45 \%$ of cases. According to the results of this study, similar nerves are affected. Changes in the peroneal nerve are the most common [42]. Renal involvement is observed significantly more often among patients with polyneuropathy [35]. Moreover, these patients have a greater extent of disease and higher ANCA titer than those without polyneuropathy [42].

Cranial nerve involvement occurs in 4.7-9\% of patients with GPA [35, 37, 42]. According to a study by Nishino et al., the most frequently affected cranial nerve is the optic nerve ( $48 \%$ of patients with cranial nerve manifestation, $3 \%$ of patients with GPA) [35]. Every cranial nerve can be affected $[35,44,45]$. Neuropathy of the sixth or seventh nerve occurs quite often as can be evidenced by the fact that it affects $38 \%$ of patients with cranial nerve manifestations ( $2.5 \%$ of patients with GPA) [35]. Adjacent orbital granuloma is the most common cause for compression of the second nerve, leading to its eventual atrophy $[44,46]$. Optic neuritis is a rare condition caused by GPA [34]. Facial nerve palsy is often related to involvement of the middle ear $[47,48]$ due to the close anatomical proximity of these structures [44]. Various authors have announced unilateral and bilateral cranial nerve manifestations $[34,35,49]$. In the literature, there are described cases of patients who suffered from palsies of all the cranial nerves apart from the first, fifth, and seventh nerves [50].
Central nervous system involvement includes three clinical categories: hypertrophic pachymeningitis, pituitary gland involvement, and cerebral vasculitis [43]. Meningitis generally occurs more frequently among patients with the limited form of GPA. About $70 \%$ (70.3\%) of cases with meningeal involvement concern patients with the localized type whereas only $10.8 \%$ and $18.9 \%$ involve patients with early systemic disease and the generalized form, respectively. The most probable reasons for such discrepancy are the easier spreading of and involvement of meninges with a granulomatous lesion in the upper respiratory tract [51]. But it should be remembered that this condition occurred with a prevalence of $0.6 \%$ in a large cohort study (324 patients) [35, 51]. The most common symptom in chronic meningitis is headache which is not a specific symptom and impedes establishment of proper diagnosis. Other neurological abnormalities generally develop during the later course of GPA development. Brain meninges are affected more frequently than spinal meninges $(87.5 \%$ vs $14.6 \%$ ). The difference between the frequencies of abnormalities concerns the types of meninges as well (changes in the dura mater equal $81.2 \%$ while changes in the leptomeninges amount to 27.1\%). Among patients with spinal cord meningitis, the patients complain of neck or back pain. But spastic paresis may occur too [51]. MRI (magnetic resonance imaging) shows bilateral diffuse symmetric linear dural thickening and enhancement but focal findings and nodular thickening are described as well [38]. A diffuse pattern of thickening was found significantly often (72.9\%) [51]. Laboratory tests show pleocytosis with dominance of leukocytes and elevated protein concentration as a coexisting or single sign [43]. Necrotizing granulomatous inflammation was the main finding $(61.5 \%)$ in meningeal biopsies. Other pathologic features, which were found in samples, were described as small vessel vasculitis, coexisting granulomatosis and vasculitis, lymphocytic inflammation, and fibrous thickening [51].

Another rare manifestation of central nervous system involvement is involvement of the pituitary gland. According to Hoffman et al. results, it occurs in $0.6 \%$ of patients with GPA [3]. In a large study, the prevalence is a little higher (1.3\%) [52]. Patients present with nonspecific symptoms: headache, asthenia, vomiting, and muscular atrophy. Muscular atrophy may be induced by taking glucocorticosteroids [53]. Visual disorders, like bitemporal hemianopsia, are observed in $17 \%$ to even $40 \%$ of cases $[43,52]$. Posterior lobe insufficiency resulting in diabetes insipidus is the most common disorder among patients with pituitary involvement $[43,53]$ and concerns $71 \%$ of cases [53]. Diabetes insipidus responds to vasopressin injections [43]. Reviewing the literature, it can be found that gonadotropin deficiency occurs in $45 \%$ of patients [53]. In some studies, the frequency of this condition was much higher (78\% [53] and 87.5\% [52]). The prevalence of hypogonadism in GPA may be underestimated because gonadotropin secretion is connected with drugs 
(glucocorticosteroids), acute illness, malnutrition, and hyperprolactinemia. Other hormonal disorders include TSH (thyroid-stimulating hormone) deficiency in $45 \%$, hyperprolactinemia in 37\%, ACTH (adrenocorticotropic hormone) deficiency in $38.8 \%$, and GH (growth hormone) deficiency in $20 \%$ [53]. Panhypopituitarism was noted in $25 \%$ of cases with pituitary dysfunction [43, 44]. Hyperprolactinemia is associated with $50 \%$ of cases with compression of the pituitary stalk [43, 44, 52]. According to other data, this correlation may be expected in even $78 \%$ of patients with hyperprolactinemia [53]. MR (magnetic resonance) imaging shows enlargement of the pituitary gland which is the most common finding and involves $80 \%$ of patients. A heterogeneous and homogeneous pattern of enhancement was described as often as an enlargement [52] although it should be emphasized that the imaging test may remain normal $[43,54]$. Other imaging findings include pseudo-adenoma, loss of posterior hypersignal on T1-weighted images, and thickening or infiltrative lesions of the pituitary stalk [53]. The gland usually returns to its normal size after successful treatment $[43,55]$. Granulomatous inflammation and inflammatory infiltrates are found in the pituitary gland tissue during biopsy $[43,53]$.

In a paper by Nishino et al., the prevalence of cerebrovascular events was $4 \%$ in patients with GPA [35]. Patients with GPA have an increased risk for stroke [56]. Central nervous vasculitis may be a cause of subarachnoid hemorrhage [57-59], intracerebral hemorrhage [60, 61], subdural hemorrhage [35, 62], arterial or venous thrombosis [63-65], and transient ischemic attack [66] or ischemic infarction of the cerebrum or spinal cord $[43,44]$. Headaches, meningeal signs, encephalopathy, psychiatric syndromes, dementia, seizures, and strokes are symptoms which may suggest central nervous system involvement $[67,68]$. The subclinical neuropsychological impairment can affect up to even $30 \%$ of patients with small vessel vasculitis [69]. Concomitant arterial hypertension, renal insufficiency, and iatrogenic impact of immunosuppressive therapy may be responsible for the symptoms mentioned above as well [67]. Cerebral vasculitis appears on MRI as white matter nonspecific lesions with high signal intensity made by the means of intermediate-weighted and T2weighted images. Granulomas may be found on MR images as well [38]. Conventional angiography is not recommended for detecting small vessel vasculitis. Biopsy has huge limits because taking a sample is not often possible [44].

\section{Cardiac Involvement}

Cardiac involvement affects $3.3-44 \%$ of patients with GPA [3, $37,70-72]$. A review of the literature provides the information that pericarditis and coronary arteritis are the most common manifestations, both with the prevalence of $50 \%$ [73]. However, a study done by Morelli et al. shows that all patients examined by means of two-dimensional Doppler and color transthoracic Doppler echocardiography have cardiac abnormalities [74]. In another paper, $42 \%$ of patients with cardiac abnormalities attributed to GPA did not complain of any cardiac symptoms [75]. CMR (cardiovascular magnetic resonance) imaging is recommended to assess cardiac involvement in GPA [76, 77].

Heart involvement is frequent in patients with life- or organ-threatening forms of GPA, who did not achieve remission despite over 6 months of induction therapy [76]. Survival rates at 1 year and 5 years are $71 \%$ and $57 \%$, respectively [75].

The frequency of pericarditis may concern even $6 \%$ of patients with GPA $[3,72]$ and may occur secondary to myocardial infarction or uremia in the course of kidney involvement [78-81]. Besides chronic constriction [71, 80], acute tamponade requiring an intervention occurs as well $[78,80$, 82]. Coronary arteritis and subsequent thromboembolism may result in myocardial infarction [83] and leads to death [84]. The frequency of myocardial infarction is evaluated at $11 \%$ between patients with cardiac manifestations [73] and the coronary artery disease concerns $2.12 \%$ of GPA cases [72]. The inflammation can spread from arterioles to coronary arteries [85]. The occlusion of small-sized and medium-sized arteries may result in myocardial ischemia. Cocco et al. reported that angina and changes in ECG (electrocardiogram) disappeared after treatment with steroids and cyclophosphamide [86]. The myocardial involvement involves granulomatous foci, perivascular inflammation, and necrotizing vasculitis [73]. Myocarditis occurs in $25 \%$ of GPA cases with cardiac manifestations [73] and may lead to cardiomyopathy. The likely cause of cardiomyopathy may be cyclophosphamide therapy [37], but the main reason is granulomatous inflammation of the myocardium [81]. Endocarditis and valvulitis occur with a prevalence of $21 \%$ and are characterized histologically by inflammation, fibrinoid necrosis, and granulomatous masses [73]. Clinically significant endocarditis is very rare but it has been found during autopsy [81]. GPA can mimic clinically infective endocarditis [78, 87]. Valvulitis may occur as primary involvement of valves or secondary to dilation of the aortic root [71] or left ventricle [78] and appears as either stenosis or regurgitation [88]. Vegetations on valves are seen as well [86, 89]. In a study by Morelli et al., first, the aortic valve was affected and thickening and prolapse of valve was observed [74]. Epicarditis is noted in $8 \%$ of patients with heart involvement and shows granulomatous inflammatory foci [73]. The involvement of the conduction system results in arrhythmias [90]. The possible causes of such arrhythmias are granulomas of the conduction system or arteritis of the atrioventricular nodal artery. The most common arrhythmias are atrial tachycardia or atrial fibrillation or flutter [78] which may be a consequence sinus node location. This structure is located near the epicardium, so pericarditis may affect adjacent elements. Periatrial position may have an impact as well. Conduction 
system granulomata were found in $17 \%$, sinus node arteritis in $13 \%$, and $\mathrm{AV}$ (atrioventricular) node arteritis in $13 \%$ of patients with cardiac involvement [73]. All types of cardiac block can occur including complete cardiac block [77, 78].

Some authors suggest that echocardiographic screening among patients with GPA may be a clinically valuable procedure because of the frequently silent course of cardiac involvement which correlates with increased morbidity $[75,91]$.

The definition of GPA includes necrotizing vasculitis concerning small-sized and medium-sized vessels but there are also known cases involving large vessels. The abdominal aorta is the most frequently affected vessel with a prevalence of $50 \%$. Abnormalities of the thoracic aorta, the subclavian artery, and the internal carotid artery are observed as well. Changes include luminal stenosis, occlusion, wall thickening, periaortitis, and aneurysms. Periaortitis occurred with the highest prevalence (46\%) [92]. An interesting case of a patient with retroperitoneal fibrosis and periaortitis was described [93]. Changes in large vessels respond well to rituximab in a case report described by Ozaki et al. [92].

\section{Skin Involvement}

There are no pathognomonic cutaneous manifestations for GPA [94]. Abnormalities of the skin occur in $14-50 \%$ of patients with GPA [3, 37, 79, 94-97] but some of these manifestations may be nonspecific or related to uremia [94]. Hu et al. showed that the amount of specific skin lesions was $28 \%$ [98] while Comfere et al. yielded results of 15\% [97]. There are many possible presentations like palpable purpura, oral ulcers, skin nodules, skin ulcers, necrotic papules, gingival hyperplasia, pustules, palpebral xanthoma, genital ulcers, digital necrosis, livedo reticularis [95], petechiae, bullae, maculae, and erythema [94]. According to the results of some studies, palpable purpura is the most common manifestation [94-97] with even 35\% of prevalence among patients with GPA and $74 \%$ of prevalence among dermatological findings [95]. A greater tendency to locate on lower limbs was observed [94] but lesions may also lie on upper limbs, head, neck [99], trunk [96], and parts of the genital organs [95]. The titer of c-ANCA was positive in $81 \%$ of cases with cutaneous manifestation. A prevalence of $79 \%$ referred to IgM (immunoglobulin M) immune deposits in leukocytoclastic vasculitis. C3 (complement component 3) deposits were observed as well but with lower occurrence [94].

A very interesting and rare cutaneous manifestation is pyoderma gangrenosum which occurs more frequently on the lower extremities as well which is the typical' localization. Obviously, other parts of the body may be affected ( atypical form'). This entity is characterized by skin necrosis and development of deep ulcers. Pyoderma gangrenosum secondary to GPA is treated with standard immunosuppressive therapy.
Kedzierska et al. presented a treatment-resistant case which was treated with dapsone and steroids and with the use of a hyperbaric chamber. The hyperbaric oxygen therapy resulted in the complete healing of wounds [100].

The histological findings include leukocytoclastic vasculitis, granulomatous inflammation, nonspecific ulceration, superficial dermal and epidermal necrosis without inflammation, erythema nodosum, granuloma annulare, chronic inflammation and acute inflammatory lesions without vasculitis. Leukocytoclastic vasculitis and granulomatous inflammation are the most common finding at biopsy both with a frequency of $31 \%$ [101]. But in another paper, the prevalence of leukocytoclastic vasculitis was much higher and equaled $80 \%$ [94].

Patients with lesions characterized by histologic features of leukocytoclastic vasculitis, palisading granuloma, granuloma vasculitis, abscess with granulomatous inflammation and necrotizing ulceration similar to pyoderma gangrenosum have higher prevalences of renal, ocular and central nervous system involvement. Furthermore, patients with cutaneous lesions are in a group with $80 \%$ risk for kidney involvement [94]. According to data from other studies, the prevalence of articular and renal involvement is higher among patients with skin changes [95] and with leukocytoclastic vasculitis. Interestingly, leukocytoclastic vasculitis is correlated with an earlier age range of GPA development and occurs approximately 15 months after the onset of GPA (35 months among patients with nonspecific chronic inflammation). The development of leukocytoclastic vasculitis compared with no skin lesions is connected with a more rapidly developing and widespread GPA [101]. The appearance of skin abnormalities may announce active systemic disease. Such appearance responded well to standard treatment in one study [95].

\section{Gastrointestinal Tract Involvement}

Some changes in the gastrointestinal tract may be caused by glucocorticosteroid therapy $[102,103]$. However, there are known cases without the use of immunosuppressant drugs $[104,105]$. The literature shows an approximate 10-26\% prevalence of gastrointestinal tract involvement [39, 104-106]. However, in a study done by Hoffman et al., there were no cases showing evidence of change in the gastrointestinal tract [3].

Patients complain of abdominal pain, gastrointestinal bleeding, dyspepsia, vomiting, and diarrhea [105]. Abdominal pain is the most common of these symptoms and affects almost all patients (97\%). Other clinical presentations occur with lower prevalence: nausea or vomiting-34\%, diarrhea-27\%, hematochezia or melena-16\%, and hematemesis$6 \%$ [107]. Differential diagnosis needs to distinguish gastrointestinal involvement secondary to GPA from coeliac 
disease, ulcerative colitis, Crohn's disease, ulceration, perforation, hemorrhage [108], and other vasculitis like ChurgStrauss syndrome and polyarteritis nodosa [102]. Some lesions due to vasculitis need surgical intervention [107].

CT (computed tomography) findings include multifocal or diffuse wall thickening, abnormal bowel wall enhancement, mesenteric vascular engorgement, and ascites [109], whereas, endoscopic examination reveals ulcerations with the majority being located in the upper gastrointestinal tract (esophageal ulcerations $-7 \%$ and gastroduodenal ulcers-17\%). Colorectal ulcerations occur in $6 \%$ of endoscopies [107]. The development of ulcers is probably caused by blood supply impairment due to vasculitis [102]. Walton et al. did not find any granuloma in the intestine but features of focal necrotizing vasculitis was noted in $24 \%$ of cases during autopsy [39] whereas, Storesund et al. proved vasculitis in 3 of 7 patients in the study. In the remaining cases, biopsy showed ulceration, ischemic changes, or inflammation [110]. But the histopathological diagnostic difficulties may result from immunosuppressive therapy administration [111].

\section{Joints and Muscles Involvement}

Articular or muscular abnormalities concern 4.7-67\% [3, 37, 112] with the main complaint being arthralgia (generally polyarthalgia [37]) of the knees, hips, wrists, or ankles [112]. The diagnosis of arthritis is established in $28 \%$ of patients. Hoffman et al. and Fauci et al. noted that articular deformities did not occur in their studies [3, 37]. Jacobs et al. presented a patient with GPA who had erosive arthritis. Lesions responded well to cyclophosphamide [113].

Articular manifestations are usually associated with disease activity [113]. The symmetrical involvement of joints and the false-positive results of rheumatoid factor lead to incorrect diagnosis of rheumatoid arthritis [3]. But there are known cases of granulomatosis overlapping with polyangiitis and rheumatoid arthritis [114]. According to the results of one paper, even one half of patients with GPA can have a positive rheumatoid factor [115].

Despite remission, a patient may still suffer from arthralgia. Fortunately, patients responded well to nonsteroidal antiinflammatory drugs in one study [37].

Muscular involvement includes myalgia, weakness, and muscle enzyme elevation [116].

Besides arthralgia, arthritis, or myalgia, there are interesting findings like soft tissue calcifications, sacroiliitis, relapsing polychondritis [115], or GPA-mimicking psoas abscess [117].

\section{Ophthalmological Involvement}

The prevalence of ocular changes occurs in $30-58 \%$ of cases $[3,37,39,79,118]$. GPA may involve the orbit, sclera, episclera, cornea, conjunctiva, eyelids, nasolacrimal system, optic nerve, retina, and uvea [119].

Orbital involvement occurs in $45 \%$ of cases of ocular and adnexal involvement and is characterized by orbital pain, proptosis, limited movements of extraocular muscles, erythematous edema of the eyelids [119], diplopia, and deterioration of vision [120]. The most common manifestation was proptosis $[3,121]$ and was refractory to treatment in a Fauci et al. study [37]. The likely mechanism of these abnormalities may be a direct result of inflammation or be caused by a spreading process from contiguous tissues [122, 123]. Retroorbital tumor mimicry was described earlier in this paper.

Eyelid abnormalities (20\% [119]) include edema, entropion, trichiasis and xanthelasma [120], and ptosis. It has been noted that eyelid involvement is most frequently associated with orbital involvement [119].

Nasolacrimal manifestations may be expected in $25 \%$ of patients with ocular and adnexal involvement [119]. The changes in the orbit may spread from dacryoadenitis [124]. The inflammation may appear recurrently. Patients complain of epiphora due to the obstruction of this gland [119]. The features of acute and chronic inflammation and focal vasculitis of small vessels are found in biopsy [125].

Inflammation of small vessels in the conjunctiva may result in conjunctivitis [126] (15\% [119]) which may lead to plaquelike lesions, ulcerating lesions [127] or avascular, necrotic tissue [128]. The involvement of conjunctiva may end in its cicatrisation [129]. Mucopurulent discharge is observed as well [119]. One study describes the prevalence of tarsal conjunctivitis among $16 \%$ of patients with GPA [128].

The involvement of episclera and sclera occurs with a frequency of $38 \%$ among patients with ophthalmic manifestations [119]. Scleritis can appear diffuse, nodular, necrotizing, softened (scleromalacia) and posterior, whereas episcleritis can appear simple and nodular [130]. The diffuse form is the most common among patients with ANCA-positive vasculitis [131]. Ocular complications connected to episcleritis and scleritis are decreased vision, anterior uveitis, peripheral ulcerative keratitis, glaucoma, and cataract [132]. There is a report of a patient who needed an enucleation due to severe pain and necrotizing scleritis [119].

Twenty-eight percent of patients with ocular and adnexal involvement have changes in the cornea. Photophobia, pain, marginal subepithelial infiltrates, pannus, thinning, and ulcerations may be possible signs and symptoms [119]. The involvement of the peripheral cornea is caused by vasculitis of intrascleral portions of the anterior ciliary arteries, perilimbal arteries, or both. Peripheral ulcerative keratitis is often bilateral [133] and is connected with $14 \%$ of cases with scleritis [132]. Descemetocele and central corneal ulcers were described as well [119, 134].

Uveal manifestations comprise $10 \%$ of ocular and adnexal involvement [119]. Anterior, intermediate, and posterior parts 
may be affected. Vitritis may coexist with these uveal manifestations [120]. Anterior uveitis is associated with scleritis [132] and is the most common form of uveitis (70\%) among patients with ANCA-positive vasculitis [131].

Retinal involvement concerns $18 \%$ of patients with ocular and adnexal involvement [119]. Fauci et al. noted retinal artery occlusion in their study [37]; however, retinal abnormalities found also include edema of the optic disk with retrobulbar mass, retinal hemorrhages and edema [119], chorioretinitis, macular edema, retinitis with cotton wool spots, acute retinal necrosis, peripheral retinitis, exudative retinal detachment, and central retinal vein occlusion. The mechanism occurring in retinal vein occlusion is probably similar to that which is responsible for renal involvement [135]. Occlusion of retinal vessels may lead to choroidal infarct $[136,137]$. Histopathological examination shows lymphocytic infiltration throughout the choroid and marked sclerosis of choroidal vessels with thickening of the media and prominent endothelial cells [137].

The involvement of the optic nerve occurs with a prevalence of $22 \%$ among patients with ocular presentations [119]. Vasculitis, acute compression, or stretching with to the point of vascular compromise may affect the optic nerve [126]. It should be kept in mind that approximately $50 \%$ of patients with retro-orbital tumor lost their vision as a result of optic nerve ischemia [3]. Anterior ischemic optic neuropathy [138] and posterior ischemic optic neuropathy [139] were observed. Eight percent of patients with eye disease lost vision in a Hoffman et al. study [3].

\section{Conclusions}

GPA is a huge challenge for contemporary diagnostics and medicine. We emphasize that every doctor should be aware of GPA's existence despite its rare prevalence. Particularly, the viability of a GPA diagnosis should be considered when a patient's condition does not improve despite a presumably proper therapeutic regimen. Our review provided the multiplicity of untypical manifestations and proved that every specialist may come into contact with a patient with GPA.

Acknowledgements The costs of this study were defrayed from regular finances of the Department of Pneumology and Allergy, Medical University of Lodz, Poland (503/1-151-03/503-11-002-18).

Authors' Contributions JMD and PL were responsible for searching the papers for the review. JMD, PL, AJB, and MRZ analyzed collected materials and wrote neurological involvement section (JMD), cardiac involvement and gastroenterological tract involvements sections (PL), joints and muscles involvement and skin involvement sections (AJB), and ophthalmological involvement section (MRZ). MRZ corrected language mistakes as a native speaker. WJP and PG review our sections and corrected them if that was necessary.

\section{Compliance with Ethical Standards}

\section{Ethics Approval and Consent to Participate Not applicable.}

Ethical Statement This article is a review. An approval of Bioethics Committee is not required.

Competing Interests The authors declare that they have no competing interests.

Abbreviations GPA, granulomatosis with polyangiitis; ANCA, antineutrophil cytoplasmic antibodies; PR3-cANCA/ c-ANCA, proteinase 3 antineutrophil cytoplasmatic antibodies; MPO, myeloperoxidase; MRI, magnetic resonance imaging; MR, magnetic resonance; TSH, thyroidstimulating hormone; $\mathrm{ACTH}$, adrenocorticotropic hormone; $\mathrm{GH}$, growth hormone; CMR, cardiovascular magnetic resonance; ECG, electrocardiogram; AV, atrioventricular; IgM, immunoglobulin $\mathrm{M}$; C3, complement component 3; CT, computed tomography

Open Access This article is distributed under the terms of the Creative Commons Attribution 4.0 International License (http:// creativecommons.org/licenses/by/4.0/), which permits unrestricted use, distribution, and reproduction in any medium, provided you give appropriate credit to the original author(s) and the source, provide a link to the Creative Commons license, and indicate if changes were made.

\section{References}

1. Greco A, Marinelli C, Fusconi M, Macri GF, Gallo A, Virgilio $\mathrm{AD}$, et al. Clinic manifestations in granulomatosis with polyangiitis. Int J Immunopathol Pharmacol. 2016;29:151-9.

2. Langford C. Clinical features and diagnosis of small-vessel vasculitis. Cleve Clin J Med. 2012;79:S3-7.

3. Hoffman GS, Kerr GS, Leavitt RY, Hallahan CW, Lebovics RS, Travis WD, et al. Wegener granulomatosis: an analysis of 158 patients. Ann Intern Med. 1992;116:488-98.

4. Appel GB, Gee B, Kashgarian M, Hayslett JP. Wegener's granulomatosis - clinical-pathologic correlations and long-term course. Am J Kidney Dis. 1981;1:27-37.

5. Regezi JA, Sciubba JJ, Jordan RCK. Oral pathology: clinical pathologic correlations. Elsevier Health Sciences; 2016.

6. Barrett AW. Wegener's granulomatosis of the major salivary glands. J Oral Pathol Med. 2012;41:721-7.

7. Cotch MF, Hoffman GS, Yerg DE, Kaufman GI, Targonski P, Kaslow RA. The epidemiology of Wegener's granulomatosis. Estimates of the five-year period prevalence, annual mortality, and geographic disease distribution from population-based data sources. Arthritis Rheum. 1996;39:87-92.

8. Haugeberg G, Bie R, Bendvold A, Larsen AS, Johnsen V. Primary vasculitis in a Norwegian community hospital: a retrospective study. Clin Rheumatol. 1998;17:364-8.

9. Koldingsnes W, Nossent H. Epidemiology of Wegener's granulomatosis in northern Norway. Arthritis Rheum. 2000;43:2481-7.

10. Watts RA, Lane SE, Bentham G, Scott DGI. Epidemiology of systemic vasculitis: a ten-year study in the United Kingdom. Arthritis Rheum. 2000;43:414-9.

11. Gibson A, Stamp LK, Chapman PT, O'Donnell JL. The epidemiology of Wegener's granulomatosis and microscopic polyangiitis in a Southern Hemisphere region. Rheumatology. 2006;45:624-8.

12. Reinhold-Keller E, Zeidler A, Gutfleisch J, Peter HH, Raspe HH, Gross WL. Giant cell arteritis is more prevalent in urban than in rural 
populations: results of an epidemiological study of primary systemic vasculitides in Germany. Rheumatology. 2000;39:1396-402.

13. Mahr A, Guillevin L, Poissonnet M, Aymé S. Prevalences of polyarteritis nodosa, microscopic polyangiitis, Wegener's granulomatosis, and Churg-Strauss syndrome in a French urban multiethnic population in 2000: a capture-recapture estimate. Arthritis Care Res. 2004;51:92-9.

14. Ntatsaki E, Watts RA, Scott DGI. Epidemiology of ANCAassociated vasculitis. Rheum Dis Clin. 2010;36:447-61.

15. Gonzalez-Gay MA, Garcia-Porrua C, Guerrero J, Rodriguez-Ledo $\mathrm{P}$, Llorca J. The epidemiology of the primary systemic vasculitides in northwest Spain: implications of the Chapel Hill Consensus Conference definitions. Arthritis Rheum. 2003;49:388-93.

16. Comarmond C, Cacoub P. Granulomatosis with polyangiitis (Wegener): clinical aspects and treatment. Autoimmun Rev. 2014;13:1121-5.

17. Gubbels SP, Barkhuizen A, Hwang PH. Head and neck manifestations of Wegener's granulomatosis. Otolaryngol Clin N Am. 2003;36:685-705.

18. Bosch X, Guilabert A, Font J. Antineutrophil cytoplasmic antibodies. Lancet. 2006;368:404-18.

19. Kallenberg CG, Heeringa P, Stegeman CA. Mechanisms of disease: pathogenesis and treatment of ANCA-associated vasculitides. Nat Clin Pract Rheumatol. 2006;2:661-70.

20. Leavitt RY, Fauci AS, Bloch DA, Michel BA, Hunder GG, Arend WP, et al. The American College of Rheumatology 1990 criteria for the classification of wegener's granulomatosis. Arthritis Rheum. 1990;33:1101-7.

21. Lutalo PMK, D'Cruz DP. Diagnosis and classification of granulomatosis with polyangiitis (aka Wegener's granulomatosis). J Autoimmun. 2014;48-49:94-8.

22. Is Wegener's granulomatosis an autoimmune disease? Current opinion in rheumatology. LWW. [cited 2016 Jul 31]. Available from: http://journals.lww.com/co-rheumatology/Fulltext/2000/ 01000/Is_Wegener_s_granulomatosis_an_autoimmune_disease_. 2.aspx.

23. Jagiello P, Gencik M, Arning L, Wieczorek S, Kunstmann E, Csernok E, et al. New genomic region for Wegener's granulomatosis as revealed by an extended association screen with 202 apoptosis-related genes. Hum Genet. 2004;114:468-77.

24. Chen M, Kallenberg CGM. The environment, geoepidemiology and ANCA-associated vasculitides. Autoimmun Rev. 2010;9: A293-8.

25. Pai P, Bone JM, Bell GM. Hydrocarbon exposure and glomerulonephritis due to systemic vasculitis. Nephrol Dial Transplant. 1998;13:1321-3.

26. Duna GF, Cotch MF, Galperin C, Hoffman DB, Hoffman GS. Wegener's granulomatosis: role of environmental exposures. Clin Exp Rheumatol. 1998;16:669-74.

27. Lane SE, Watts RA, Bentham G, Innes NJ, Scott DGI. Are environmental factors important in primary systemic vasculitis?: a case-control study. Arthritis Rheum. 2003;48:814-23.

28. Ferri FF. Ferri's clinical advisor 2016: 5 books in 1. Elsevier Health Sciences; 2015.

29. Almouhawis HA, Leao JC, Fedele S, Porter SR. Wegener's granulomatosis: a review of clinical features and an update in diagnosis and treatment. J Oral Pathol Med. 2013;42:507-16.

30. Mukhtyar C, Guillevin L, Cid MC, Dasgupta B, de Groot K, Gross W, et al. EULAR recommendations for the management of primary small and medium vessel vasculitis. Ann Rheum Dis. 2009;68:310-7.

31. Pagnoux C, Guillevin L. Treatment of granulomatosis with polyangiitis (Wegener's). Expert Rev Clin Immunol. 2015;11:339-48.

32. Holle JU, Gross WL. Treatment of ANCA-associated vasculitides (AAV). Autoimmun Rev. 2013;12:483-6.
33. Langford CA. Update on the treatment of granulomatosis with polyangiitis (Wegener's). Curr Treat Options Cardiovasc Med. 2012;14:164-76.

34. Bilateral optic neuritis in Wegener granulomatosis : journal of neuro-ophthalmology. LWW. [cited 2016 Nov 20]. Available from: http://journals.lww.com/jneuro-ophthalmology/Fulltext/ 2005/03000/Bilateral_Optic_Neuritis_in_Wegener_ Granulomatosis.7.aspx.

35. Nishino H, Rubino FA, DeRemee RA, Swanson JW, Parisi JE. Neurological involvement in Wegener's granulomatosis: an analysis of 324 consecutive patients at the Mayo Clinic. Ann Neurol. 1993;33:4-9.

36. Moore PM, Cupps TR. Neurological complications of vasculitis. Ann Neurol. 1983;14:155-67.

37. Fauci AS. Wegener's granulomatosis: prospective clinical and therapeutic experience with 85 patients for 21 years. Ann Intern Med. 1983;98:76.

38. Murphy JM, Gomez-Anson B, Gillard JH, Antoun NM, Cross J, Elliott JD, et al. Wegener granulomatosis: MR imaging findings in brain and meninges. Radiology. 1999;213:794-9.

39. Walton EW. Giant-cell granuloma of the respiratory tract (Wegener's granulomatosis). Br Med J. 1958;2:265-70.

40. Anderson JM, Jamieson DG, Jefferson JM. Non-healing granuloma and the nervous system. QJM. 1975;44:309-23.

41. Reinhold-Keller E, Beuge N, Latza U, De Groot K, Rudert H, Nölle B, et al. An interdisciplinary approach to the care of patients with Wegener's granulomatosis: long-term outcome in 155 patients. Arthritis Rheum. 2000;43:1021-32.

42. de Groot K, Schmidt DK, Arlt AC, Gross WL, Reinhold-Keller E. Standardized neurologic evaluations of 128 patients with Wegener granulomatosis. Arch Neurol. 2001;58:1215-21.

43. Central nervous system involvement in Wegener granulomatosis: medicine. LWW. [cited 2016 Nov 25]. Available from: http:// journals.lww.com/md-journal/Fulltext/2006/01000/Central Nervous_System_Involvement_in_Wegener.6.aspx.

44. Neurological involvement in Wegener's granulomatosis: current opinion in rheumatology. LWW. [cited 2016 Nov 26]. Available from: http://journals.lww.com/co-rheumatology/Fulltext/2011/ 01000/Neurological involvement in Wegener s.3.aspx.

45. Laudien M, Lamprecht P, Hedderich J, Holle J, Ambrosch P. Olfactory dysfunction in Wegener's granulomatosis. Rhinology. 2009;47:254-9.

46. Pakalniskis MG, Berg AD, Policeni BA, Gentry LR, Sato Y, Moritani $\mathrm{T}$, et al. The many faces of granulomatosis with polyangiitis: A review of the head and neck imaging manifestations. Am J Roentgenol. 2015;205:W619-29.

47. Rasmussen N. Management of the ear, nose, and throat manifestations of Wegener granulomatosis: an otorhinolaryngologist's perspective. Curr Opin Rheumatol. 2001;13:3-11.

48. Takagi D, Nakamaru Y, Maguchi S, Furuta Y, Fukuda S. Otologic manifestations of Wegener's granulomatosis. Laryngoscope. 2002;112:1684-90.

49. Wawrzecka A, Szymańska A, Jeleniewicz R, Szymański M. Granulomatosis with polyangiitis with bilateral facial palsy and severe mixed hearing loss. Case Rep Otolaryngol. 2016. [cited 2016 Nov 26]. Available from: http://www.ncbi.nlm.nih.gov/ pmc/articles/PMC4963591/.

50. Ahmed SV, Chandra S. Widespread cranial nerve palsies while on cyclophosphamide therapy: a very rare manifestation of Wegener's granulomatosis (granulomatosis with polyangitis). BMJ Case Rep. 2013 [cited 2016 Nov 26]. Available from: http://www.ncbi.nlm.nih.gov/pmc/articles/PMC3822178/.

51. Meningeal involvement in Wegener's granulomatosis is associated with localized disease. [cited 2016 Nov 26]. Available from: $\mathrm{http} / / /$ www.clinexprheumatol.org/abstract.asp?a=2847. 
52. Kapoor E, Cartin-Ceba R, Specks U, Leavitt J, Erickson B, Erickson D. Pituitary dysfunction in granulomatosis with polyangiitis: the Mayo Clinic experience. J Clin Endocrinol Metab. 2014;99:3988-94.

53. De Parisot A, Puéchal X, Langrand C, Raverot G, Gil H, Perard L, et al. Pituitary involvement in granulomatosis with polyangiitis. Medicine (Baltimore). 2015 [cited 2016 Nov 27]. Available from: http://www.ncbi.nlm.nih.gov/pmc/articles/PMC4602700/.

54. Hurst NP, Dunn NA, Chalmers TM. Wegener's granulomatosis complicated by diabetes insipidus. Ann Rheum Dis. 1983;42: 600-1.

55. Katzman GL, Langford CA, Sneller MC, Koby M, Patronas NJ. Pituitary involvement by Wegener's granulomatosis: a report of two cases. Am J Neuroradiol. 1999;20:519-23.

56. Aviña-Zubieta JA, Mai A, Amiri N, Dehghan N, Tan JA, Sayre $\mathrm{EC}$, et al. Risk of myocardial infarction and stroke in patients with granulomatosis with polyangiitis: a population-based study. Arthritis Rheumatol. 2016;n/a-n/a.;68:2752-9.

57. Cruz DN, Segal AS. A patient with Wegener's granulomatosis presenting with a subarachnoid hemorrhage: case report and review of CNS disease associated with Wegener's granulomatosis. Am J Nephrol. 1997;17:181-6.

58. Venning MC, Burn DJ, Bashir SH, Deopujari CE, Mendelow AD. Subarachnoid haemorrhage in Wegener's granulomatosis, with negative four vessel angiography. Br J Neurosurg. 1991;5:195-8.

59. Recurrent subarachnoid hemorrhage in a 17 year old with Wege... : JCR: journal of clinical rheumatology. LWW. [cited 2016 Dec 5]. Available from: http://journals.lww.com/jclinrheum/Fulltext/ 2006/08000/Recurrent_Subarachnoid_Hemorrhage_in_a_17 Year_Old.16.aspx.

60. Ceri M, Ortabozkoyun L, Unverdi S, Kirac M, Duranay M. Massive intracerebral hemorrhage associated with Wegener granulomatosis. Rheumatol Int. 2012;32:1813-4.

61. Wegener granulomatosis with massive intracerebral hemorrhage...: JCR: Journal of Clinical Rheumatology. LWW. [cited 2016 Dec 5]. Available from: http://journals.lww.com/ jclinrheum/Fulltext/2005/12000/Wegener_Granulomatosis_ With Massive_Intracerebral.5.aspx.

62. Kalra S, Yadav A, Agarwal S, Kumar S. Wegener's granulomatosis with subdural hematoma as the initial manifestation. Int J Crit Illn Inj Sci. 2013;3:88-90.

63. Hammans SR, Ginsberg L. Superior sagittal sinus thrombosis in Wegener's granulomatosis. J Neurol Neurosurg Psychiatry. 1989;52:287.

64. Mickle JP, McLennan JE, Chi JG, Lidden CW. Cortical vein thrombosis in Wegener's granulomatosis. J Neurosurg. 1977;46: 248-51.

65. Satoh J, Miyasaka N, Yamada T, Nishido T, Okuda M, Kuroiwa T, et al. Extensive cerebral infarction due to involvement of both anterior cerebral arteries by Wegener's granulomatosis. Ann Rheum Dis. 1988;47:606-11.

66. Provenzale JM, Allen NB. Wegener granulomatosis: CT and MR findings. Am J Neuroradiol. 1996;17:785-92.

67. Sivakumar MR, Chandrakantan A. A rare case of stroke in Wegener's granulomatosis. Cerebrovasc Dis. 2002;13:143-4.

68. Ferro JM. Vasculitis of the central nervous system. J Neurol. 1998;245:766-76.

69. Mattioli F, Capra R, Rovaris M, Chiari S, Codella M, Miozzo A, et al. Frequency and patterns of subclinical cognitive impairment in patients with ANCA-associated small vessel vasculitides. J Neurol Sci. 2002;195:161-6.

70. Florian A, Slavich M, Blockmans D, Dymarkowski S, Bogaert J. Cardiac involvement in granulomatosis with polyangiitis (Wegener granulomatosis). Circulation. 2011;124:e342-4.
71. Grant SC, Levy RD, Venning MC, Ward C, Brooks NH. Wegener's granulomatosis and the heart. Br Heart J. 1994;71: $82-6$.

72. McGeoch L, Carette S, Cuthbertson D, Hoffman GS, Khalidi N, Koening CL, et al. Cardiac involvement in granulomatosis with polyangiitis. J Rheumatol. 2015;42:1209-12.

73. Forstot JZ, Overlie PA, Neufeld GK, Harmon CE, Forstot SL. Cardiac complications of wegener granulomatosis: a case report of complete heart block and review of the literature. Semin Arthritis Rheum. 1980;10:148-54.

74. Morelli S, Castelmenardo AMGD, Conti F, Sgreccia A, Alessandri C, Bernardo ML, et al. Cardiac involvement in patients with Wegener's granulomatosis. Rheumatol Int. 2000;19:209-12.

75. Oliveira GHM, Seward JB, Tsang TSM, Specks U. Echocardiographic findings in patients with Wegener granulomatosis. Mayo Clin Proc. 2005;80:1435-40.

76. Miszalski-Jamka T, Szczeklik W, Sokołowska B, MiszalskiJamka K, Karwat K, Grządziel G, et al. Cardiac involvement in Wegener's granulomatosis resistant to induction therapy. Eur Radiol. 2011;21:2297-304.

77. Brihaye B, Aouba A, Pagnoux C, Vignaux O, Le Hello C, Guillevin L. Rituximab reversed cardiac involvement of Wegener's granulomatosis: magnetic resonance imaging assessment. Presse Med. 2008;37:412-5.

78. Goodfield NE, Bhandari S, Plant WD, Morley-Davies A, Sutherland GR. Cardiac involvement in Wegener's granulomatosis. Br Heart J. 1995;73:110-5.

79. Wegener's granulomatosis: studies in eighteen patients and a... : Medicine. LWW. [cited 2016 Dec 11]. Available from: http:// journals.lww.com/md-journal/Fulltext/1973/11000/WEGENER S GRANULOMATOSIS STUDIES IN EIGHTEEN.2.aspx.

80. Schiavone WA, Ahmad M, Ockner SA. Unusual cardiac complications of Wegener's granulomatosis. Chest. 1985;88:745-8.

81. Marques N, Mimoso J, Bohorquez R, Lázaro M, Brito H, Pereira MA, et al. Unstable angina as initial manifestation of Wegener granulomatosis: case report. Rev Port Cardiol Orgao Of Soc Port Cardiol Port J Cardiol Off J Port Soc Cardiol. 2008;27:1469-77.

82. Meryhew NL, Bache RJ, Messner RP. Wegeners granulomatosis with acute pericardial tamponade. Arthritis Rheum. 1988;31:300 2 .

83. Lazarus MN, Khurana R, Sethi AS, Naughton MA. Wegener's granulomatosis presenting with an acute ST-elevation myocardial infarct (STEMI). Rheumatology. 2006;45:916-8.

84. Morbini P, Dal Bello B, Arbustini E. Coronary artery inflammation and thrombosis in Wegener's granulomatosis-polyarteritis nodosa overlap syndrome. G Ital Cardiol. 1998;28:377-82.

85. MR imaging of cardiac mass in Wegener granulomatosis. Journal of Computer Assisted Tomography. LWW. [cited 2016 Dec 27]. Available from: http:/journals.lww.com/jcat/Fulltext/1991/11000/ MR Imaging of Cardiac Mass in Wegener.24.aspx.

86. Cocco G, Gasparyan AY. Myocardial ischemia in Wegener's granulomatosis: coronary atherosclerosis versus vasculitis. Open Cardiovasc Med J. 2010;4:57-62.

87. Parameswaran R, Ramakrishnan B, Prabu M, Ramachandran B An unusual cause for fever of unknown origin in a patient with a prosthetic valve. BMJ Case Rep. 2009 [cited 2016 Dec 22]. Available from: http://www.ncbi.nlm.nih.gov/pmc/articles/ PMC3027500/.

88. Martinez F, Chung JH, Digumarthy SR, Kanne JP, Abbott GF, Shepard J-AO, et al. Common and uncommon manifestations of Wegener granulomatosis at chest CT: radiologic-pathologic correlation. RadioGraphics. 2011;32:51-69.

89. Anthony DD, Askari AD, Wolpaw T, McComsey G. Wegener granulomatosis simulating bacterial endocarditis. Arch Intern Med. 1999;159:1807-10. 
90. Allen DC, Doherty CC, O'Reilly DP. Pathology of the heart and the cardiac conduction system in Wegener's granulomatosis. $\mathrm{Br}$ Heart J. 1984;52:674-8.

91. Hazebroek MR, Kemna MJ, Schalla S, Wijk SS, Gerretsen SC, Dennert R, et al. Prevalence and prognostic relevance of cardiac involvement in ANCA-associated vasculitis: eosinophilic granulomatosis with polyangiitis and granulomatosis with polyangiitis. Int J Cardiol. 2015;199:170-9.

92. Ozaki T, Maeshima K, Kiyonaga Y, Torigoe M, Imada C, Hamasaki $\mathrm{H}$, et al. Large-vessel involvement in granulomatosis with polyangiitis successfully treated with rituximab: a case report and literature review. Mod Rheumatol. 2015;1-6.

93. González Revilla EM, Fernandez AA, Ramirez MTR, Pardo SC, Moragues MAJ. Retroperitoneal fibrosis with periaortitis: a case report of an unusual form of presentation of granulomatosis with polyangiitis. Respir Med Case Rep. 2016;19:121-4.

94. Daoud MS, Gibson LE, DeRemee RA, Specks U, el-Azhary RA, Daniel Su WP. Cutaneous Wegener's granulomatosis: clinical, histopathologic, and immunopathologic features of thirty patients. J Am Acad Dermatol. 1994;31:605-12.

95. Francès C, Du LTH, Piette J-C, Saada V, Boisnic S, Wechsler B, et al. Wegener's granulomatosis: dermatological manifestations in 75 cases with clinicopathologic correlation. Arch Dermatol. 1994;130:861-7.

96. Patten SF, Tomecki KJ. Wegener's granulomatosis: cutaneous and oral mucosal disease. J Am Acad Dermatol. 1993;28:710-8.

97. Comfere NI, Macaron NC, Gibson LE. Cutaneous manifestations of Wegener's granulomatosis: a clinicopathologic study of 17 patients and correlation to antineutrophil cytoplasmic antibody status. J Cutan Pathol. 2007;34:739-47.

98. Hu C-H, O'Loughlin S, Winkelmann RK. Cutaneous manifestations of Wegener granulomatosis. Arch Dermatol. 1977;113:17582.

99. Gibson LE, Specks U, Homburger H. Clinical utility of ANCA tests for the dermatologist. Int J Dermatol. 2003;42:859-69.

100. Kedzierska K, Sindrewicz K, Smektała T, Wiśniewska M, Masiuk M, Staniszewska E, et al. Wegener's granulomatosis and pyoderma gangrenosum-rare causes of facial ulcerations. Postepy Hig Med Dosw Online. 2016;70:210-8.

101. Cutaneous pathology in Wegener's granulomatosis: the American Journal of Surgical Pathology. LWW. [cited 2016 Dec 31]. Available from: http://journals.lww.com/ajsp/Fulltext/1995/ 02000/Cutaneous_Pathology_in_Wegener_s_Granulomatosis_5. aspx.

102. Deniz K, Ozșeker HS, Balas S, Akpýnar E, Sökmensüer C. Intestinal involvement in Wegener's granulomatosis. J Gastrointest Liver Dis JGLD. 2007;16:329-31.

103. Geraghty J, Mackay IR, Smith DC. Intestinal perforation in Wegener's granulomatosis. Gut. 1986;27:450-1.

104. Haworth SJ, Pusey CD. Severe intestinal involvement in Wegener's granulomatosis. Gut. 1984;25:1296-300.

105. Gastrointestinal tract involvement in granulomatosis with polyangiitis. Gastroenterol Rev Gastroenterol. [cited 2017 Jan 1]; Available from: http://www.termedia.pl/Gastrointestinal-tractinvolvement-in-granulomatosis-with-polyangiitis,41,26945,1,0. html.

106. Takwoingi YM, Dempster JH. Wegener's granulomatosis: an analysis of 33 patients seen over a 10 -year period. Clin Otolaryngol Allied Sci. 2003;28:187-94.

107. Presentation and outcome of gastrointestinal involvement in...: Medicine. LWW. [cited 2017 Jan 1]. Available from: http:// journals.lww.com/md-journal/Fulltext/2005/03000/Presentation and_Outcome_of_Gastrointestinal.6.aspx.

108. Camilleri M, Pusey CD, Chadwick VS, Rees AJ. Gastrointestinal manifestations of systemic vasculitis. Q J Med. 1983;52:141-9.
109. Pickhardt PJ, Curran VW. Fulminant enterocolitis in Wegener's granulomatosis. Am J Roentgenol. 2001;177:1335-7.

110. Storesund B, Gran JT, Koldingsnes W. Severe intestinal involvement in Wegener's granulomatosis: report of two cases and review of the literature. Rheumatology. 1998;37:387-90.

111. Akça T, Çolak T, Çağlıkülekçi M, Öcal K, Aydın S. Intestinal perforation in Wegener's granulomatosis: a case report. Ulus Travma Acil Cerrahi Derg. 2005;11:348-51.

112. Frosch M, Foell D. Wegener granulomatosis in childhood and adolescence. Eur J Pediatr. 2004;163:425-34.

113. Jacobs RP, Moore M, Brower A. Wegener's granulomatosis presenting with erosive arthritis. Arthritis Rheum. 1987;30:943-6.

114. Douglas G, Bird K, Flume P, Silver R, Bolster M. Wegener's granulomatosis in patients with rheumatoid arthritis. J Rheumatol. 2003;30:2064-9.

115. Noritake DT, Weiner SR, Bassett LW, Paulus HE, Weisbart R. Rheumatic manifestations of Wegener's granulomatosis. J Rheumatol. 1987;14:949-51.

116. Puéchal X. Antineutrophil cytoplasmic antibody-associated vasculitides. Joint Bone Spine. 2007;74:427-35.

117. Nossent H, Eggen T. Wegener's granulomatosis mimicking psoas abscess. J Rheumatol. 2002;29:1578-80.

118. Abdou NI, Kullman GJ, Hoffman GS, Sharp GC, Specks U, McDonald T, et al. Wegener's granulomatosis: survey of $701 \mathrm{pa}-$ tients in North America. Changes in outcome in the 1990s. J Rheumatol. 2002;29:309-16.

119. Bullen CL, Liesegang TJ, McDonald TJ, DeRemee RA. Ocular complications of Wegener's granulomatosis. Ophthalmology. 1983;90:279-90.

120. Kubaisi B, Abu Samra K, Foster CS. Granulomatosis with polyangiitis (Wegener's disease): an updated review of ocular disease manifestations. Intractable Rare Dis Res. 2016;5:61-9.

121. Isa H, Lightman S, Luthert PJ, Rose GE, Verity DH, Taylor SR. Histopathological features predictive of a clinical diagnosis of ophthalmic granulomatosis with polyangiitis (GPA). Int J Clin Exp Pathol. 2012;5:684-9.

122. Bitik B, Kılıç L, Küçükșahin O, Şahin K, Tufan A, Karadağ Ö, et al. Retro-orbital granuloma associated with granulomatosis with polyangiitis: a series of nine cases. Rheumatol Int. 2014;35:108392.

123. Pakrou N, Selva D, Leibovitch I. Wegener's granulomatosis: ophthalmic manifestations and management. Semin Arthritis Rheum. 2006;35:284-92.

124. Lopes Caçola R, Morais SA, Carvalho R, Môço R. Bilateral dacryoadenitis as initial presentation of a locally aggressive and unresponsive limited form of orbital granulomatosis with polyangiitis. BMJ Case Rep. 2016;2016.

125. Lanza JT, Ku Y, Lucente FE, Har-El G. Wegener's granulomatosis of the orbit: lacrimal gland involvement as a major sign. Am J Otolaryngol. 1995;16:119-22.

126. Haynes BF, Fishman ML, Fauci AS, Wolff SM. The ocular manifestations of Wegener's granulomatosis. Am J Med. 1977;63: 131-41.

127. Jordan DR, Addison DJ. Wegener's granulomatosis. Ophthalmology. 1994;101:602-7.

128. Robinson MR, Lee SS, Sneller MC, Lerner R, Langford CA, Talar-Williams C, et al. Tarsal-conjunctival disease associated with Wegener's granulomatosis. Ophthalmology. 2003;110: 1770-80.

129. Meier FM, Messmer EP, Bernauer W. Wegener's granulomatosis as a cause of cicatrising conjunctivitis. Br J Ophthalmol. 2001;85: 625.

130. Watson PG, Hayreh SS. Scleritis and episcleritis. Br J Ophthalmol. 1976;60:163-91. 
131. Watkins AS, Kempen JH, Choi D, Liesegang TL, Pujari SS, Newcomb C, et al. Ocular disease in patients with ANCApositive vasculitis. J Ocul Biol Dis Infor. 2009;3:12-9.

132. de la Maza MS, Jabbur NS, Foster CS. Severity of scleritis and episcleritis. Ophthalmology. 1994;101:389-96.

133. Messmer EM, Foster CS. Vasculitic peripheral ulcerative keratitis. Surv Ophthalmol. 1999;43:379-96.

134. Aw B, Si B, Fe C, Jg L. Corneal perforation in Wegener's granulomatosis treated with corneal transplantation: case report. Ann Ophthalmol. 1977;9:799-801.

135. Wang M, Khurana RN, Sadda SR. Central retinal vein occlusion in Wegener's granulomatosis without retinal vasculitis. Br J Ophthalmol. 2006;90:1435-6.

136. Mirza S, Ram ARR, Bowling BS, Nessim M. Central retinal artery occlusion and bilateral choroidal infarcts in wegener's granulomatosis. Eye. 1999;13:374-6.
137. Iida T, Spaide RF, Kantor J. Retinal and choroidal arterial occlusion in Wegener's granulomatosis1. Am J Ophthalmol. 2002;133: $151-2$.

138. Howe L, D'Cruz D, Chopdar A, Hughes G. Anterior ischaemic optic neuropathy in Wegener's granulomatosis. Eur J Ophthalmol. 1994;5: 277-9.

139. Nagashima T, Matsumoto K, Murosaki T, Okada M, Iwamoto M, Makino S, et al. Posterior ischemic optic neuropathy in a patient with granulomatosis with polyangiitis (Wegener's). Rheumatol Int. 2013;33:1915-6.

Publisher's Note Springer Nature remains neutral with regard to jurisdictional claims in published maps and institutional affiliations. 